14.1

\title{
Жизнеспособность клеток различных типов, культивируемых на поверхности медицинского электрета
}

\author{
() О.И. Александрова, ${ }^{1}$ С.А. Александрова, ${ }^{1}$ В.П. Хомутов, ${ }^{2}$ М.С. Моргунов, ${ }^{2}$ М.И. Блинова ${ }^{1}$ \\ ${ }^{1}$ Институт цитологии РАН, \\ 194064 Санкт-Петербург, Россия \\ ${ }^{2} \mathrm{OOO}$ „Медэл“, \\ 194044 Санкт-Петербург, Россия \\ e-mail: elga.aleks@gmail.com
}

(Поступило в Редакцию 9 февраля 2018 г.)

\begin{abstract}
Проведено исследование in vitro влияния электрического поля медицинского электрета на основе пятиокиси тантала $\left(\mathrm{Ta}_{2} \mathrm{O}_{5}\right)$ на жизнеспособность фибробластов, мультипотентных мезенхимных стромальных клеток костного мозга, остеоцитов и хондроцитов человека, культивируемых на поверхности танталовых ортопедических имплантатов с электретным покрытием. При помощи методов фотоколориметрического анализа и сканирующей электронной микроскопии выявлены различия в метаболической активности и морфологии клеток, характере прикрепления клеток к имплантатам и распределения по их поверхности, связанные с величиной и характером распределения электрического заряда по поверхности этих имплантатов и типом клеточных тест-систем. Неясность механизмов действия электрического поля медицинских электретов на функциональную активность различных типов клеток и тканей организма диктуют необходимость дальнейших экспериментальных разработок и фундаментальных исследований в этой области.
\end{abstract}

DOI: $10.21883 /$ JTF.2018.09.46419.58-18

\section{Введение}

В последние годы все большее развитие получает направление медицины, основанное на использовании для стимулирования позитивных биологических процессов в организме человека близкодействующих статических электрических полей, созданных автономно функционирующими электретами [1]. Электреты - электрические аналоги постоянных магнитов, физика работы которых основана на достаточно сложных явлениях, лежащих в основе так называемого электретного состояния диэлектриков [2]. Электреты относятся к классу активных диэлектриков и представляют собой материалы, способные после снятия внешнего воздействия сохранять длительное время (многие месяцы и даже годы) остаточную поляризацию и генерировать сравнительно сильное (до $10^{6} \mathrm{~V} / \mathrm{m}$ ) квазистатическое (медленно меняющееся во времени) электрическое поле. Наряду с полем электретам присущ весьма слабый электрический ток (плотность $10^{-14} \mathrm{~A} / \mathrm{mm}^{2}$ ), который течет по градиенту напряжения поля. Этот ток, многократно возрастающий при нагревании электрета, называют термостимулированным током (ТСТ). Совокупность проявлений электрета (электрическое поле и ТСТ) называют электретным эффектом [3,4].

Благодаря своим свойствам электреты могут применяться в качестве своеобразных аккумуляторов электрической энергии. На этом и основан интерес прикладного характера к электретному эффекту, который не угасает с момента разработки первого метода создания электрета из карнаубского воска и смолы и первых экспериментов с ним [5]. В настоящее время практически все известные органические и неорганические диэлектрики могут быть переведены в электретное состояние. Возникновение электретного состояния в диэлектриках связано с дипольной поляризацией, смещением зарядов внутри молекул или доменных структур, образованием пространственного или поверхностного заряда. Известно несколько способов получения стабильных электретов, основанных на изменении их внутреннего электрического поля под влиянием различных воздействий. Термоэлектреты получают, нагревая, а затем охлаждая диэлектрик в сильном электрическом поле; фотоэлектреты - освещая его в сильном электрическом поле; радиоэлектреты - облучая радиоактивным излучением; электроэлектреты - поляризацией в сильном электрическом поле без нагревания; магнитоэлектреты поляризацией в магнитном поле; механоэлектреты механической деформацией; трибоэлектреты - трением; короноэлектреты - действием поля коронного разряда; металлополимерные электреты - поляризацией полимеров в контакте с электродами из разнородных металлов [2,6].

Без малого сто лет электреты активно применяются в технике. Исследования возможности использования электретов в медицине для стимуляции позитивных биологических процессов начались только на рубеже 60-70-х годов прошлого века, когда стало известно, что многие ткани живого организма находятся в электретном состоянии, которое было определено как биоэлектретное состояние [7-9]. Феноменологическое описание биоэлектретного эффекта живых тканей дало твердое основание для продолжения активного изучения влияния электрических полей как в эксперименте, так и при 
проведении клинических исследований. На основании полученных исследователями данных была выдвинута гипотеза, что при контакте с биологическими тканями электрет может своим полем оказывать дозированное локальное воздействие на электретные свойства тканей поврежденного органа, способствуя его репарации в оптимальных биофизических условиях. Это инициировало исследования, направленные на оценку влияния медицинских электретов на репарацию различных тканей организма [4,10-14]. Наиболее активно рассматривается вопрос по влиянию отрицательно заряженных электретов на остеогенез и репаративную регенерацию костной ткани. Результаты этих исследований демонстрируют, что коррекция нарушений биоэлектрических процессов при различных заболеваниях и повреждениях опорнодвигательной системы посредством электрического поля электрета улучшает условия для остеорепарации и восстановления структур костной ткани. Применение электретов при остеосинтезе сокращает сроки лечения и сводит к минимуму послеоперационные осложнения. Есть данные по успешному применению электретов для ускорения срастания мягких тканей с костью, стимуляции регенерации мягких тканей и свежих переломов, а также некоторые другие работы, показывающие возможность эффективного использования электретов в медицине [15].

Несмотря на положительные результаты, электреты долгое время находили в медицине очень ограниченное применение, что связано с некоторыми трудностями получения электретов с нужными характеристиками и долговременной стабильностью. В 80-90-е гг. прошлого века активно использовались медицинские электреты в виде тонких полимерных пленок из тефлонов типа полифторэтиленпропилена (FEP) и политетрафторэтилена (PTFE) или поливинилиденфторида (PVDF). Проводились исследования по применению электретной керамики при сращивании переломов и восстановлении утерянных участков кости. В последние годы большой интерес вызывают медицинские электреты в виде пленок оксида тантала. В настоящее время имплантаты с покрытием из $\mathrm{Ta}_{2} \mathrm{O}_{5}$ успешно применяют в травматологии и ортопедии для получения устройств, оптимизирующих процессы остеорепарации при лечении переломов и ложных суставов костей, деформирующих артрозов крупных суставов, в челюстно-лицевой хирургии и ортопедической стоматологии при лечении травматических повреждений костей лицевого черепа и дентальной имплантации. Ведутся разработки по использованию пленок $\mathrm{Ta}_{2} \mathrm{O}_{5}$ в хирургии, кардиохирургии, косметологии, эндопротезировании [16-19].

При разработке медицинских электретов для различных областей медицины помимо выбора материала электрета необходимо учитывать характеристики его электрического поля (полярность, величина и характер распределения статического заряда по поверхности) и электрические свойства тканей организма. Так, известно, что формирование новообразующихся костных структур происходит в области отрицательных зарядов, а в области положительных зарядов - резорбция костной ткани [20]. Для нервной ткани показано, что положительно заряженная поверхность вызывает значительно большее разрастание нейронов, чем отрицательно заряженная или незаряженная [21]. Механизмы этого влияния и их физические закономерности в настоящее время до конца не изучены. Практическая потребность получения электретов с заданными свойствами стимулировала и продолжает стимулировать исследования в этой области. Для оценки взаимодействия биоматериалов с тканями организма в качестве упрощенных моделей в последнее время все чаще применяют культуры клеток, которые особенно перспективны для предварительной оценки (экспресс-методы) биосовместимости материалов. Целью настоящей работы явилось исследование влияния электрического поля медицинского электрета на основе пятиокиси тантала $\left(\mathrm{Ta}_{2} \mathrm{O}_{5}\right)$ на жизнеспособность различных типов клеток человека в условиях in vitro.

\section{Материалы и методы}

Для проведения экспериментов in vitro были изготовлены модели танталовых ортопедических имплантатов, применяемых при внутреннем остеосинтезе для профилактики и лечения заболеваний опорно-двигательного аппарата, например при сращивании переломов, восстановлении утраченных участков кости, для лечения артрозов суставов (коленного, тазобедренного и др.). Модели имплантатов были выполнены в форме дисков различного диаметра толщиной $0.5 \mathrm{~mm}$. Для их изготовления использовался прокат тантала высокой чистоты $(99.92 \%)$, обезжиренного и отожженного в вакууме $10^{-5}$ Torr при температуре $1900^{\circ} \mathrm{C}$. В качестве электретного покрытия применяли пленку анодного оксида тантала $\left(\mathrm{Ta}_{2} \mathrm{O}_{5}\right)$ толщиной около $300 \mathrm{~nm}$, выращенную на дисках тантала и содержащую приповерхностный отрицательный электронный заряд плотностью $0.048-0.056 \mathrm{C} / \mathrm{m}^{2}$, закрепленный на глубоких потенциальных ловушках. Для получения $\mathrm{Ta}_{2} \mathrm{O}_{5}$ диски тантала анодно окислялись в водном растворе ортофосфорной кислоты, затем отжигались на воздухе для улучшения диэлектрических и электретных свойств, электризовались с использованием водного контакта и подвергались дополнительному отжигу для термостабилизации электретного состояния. Стерилизацию проводили плазменным методом. В работе исследовали два варианта электретов: образцы с равномерным распределением заряда по поверхности, но с электретной разностью потенциалов между поверхностью оксида и танталом основы $U_{e}=60-70 \mathrm{~V}$ и образцы с распределением заряда по поверхности, близким к линейному; в этом случае $U_{e}$ изменялось от 0 до $60-70 \mathrm{~V}$. Для контроля служили диски тантала без электретного покрытия.

В качестве модельных тест-систем использовали клетки человека: мультипотентные мезенхимные стромаль- 

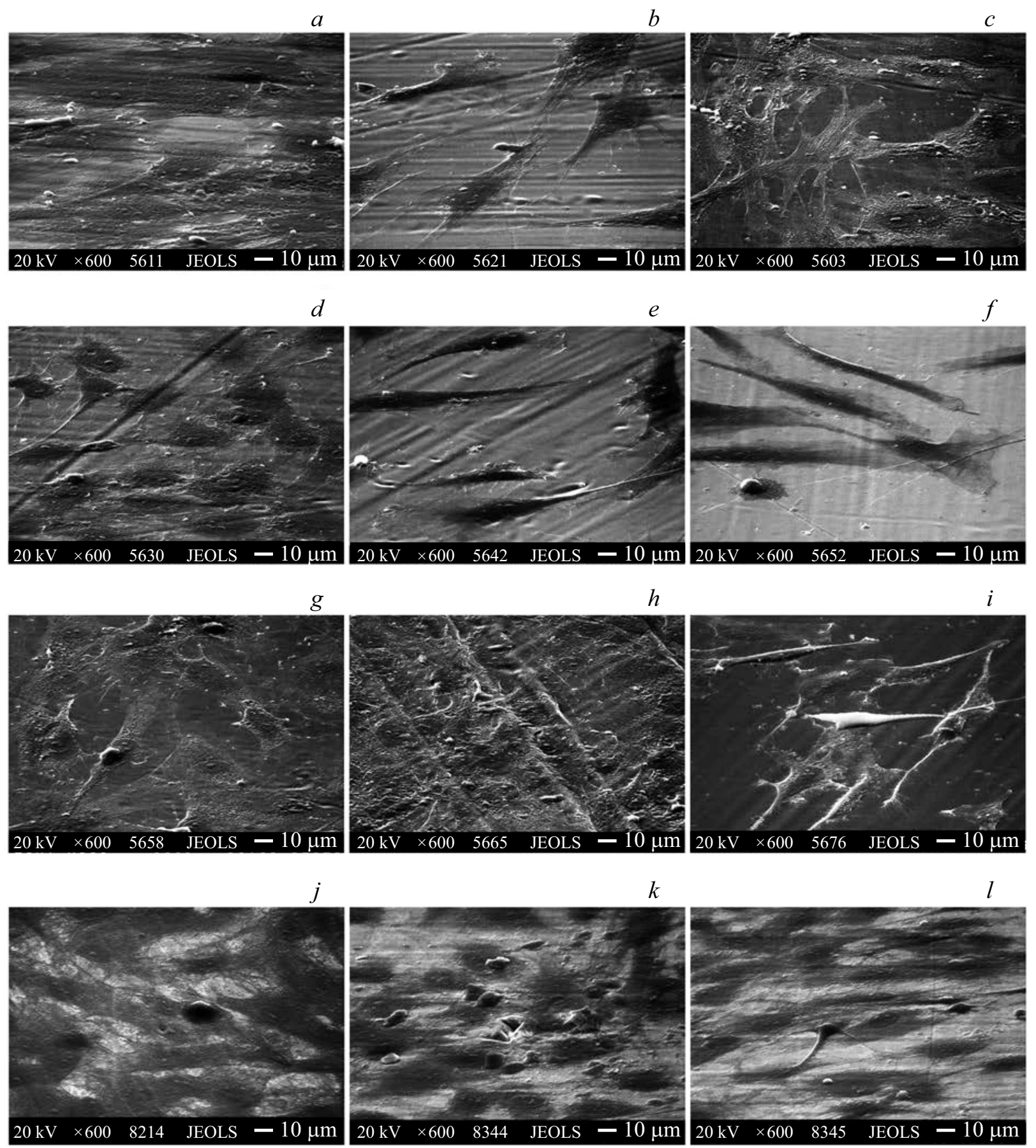

Рис. 1. Результаты СЭМ. ММСК $(a-c)$, остеоциты $(d-f)$, хондроциты $(g-i)$ и ФК $(j-l)$, культивируемые в течение одних суток на поверхности медицинских электретов $\mathrm{Ta}_{2} \mathrm{O}_{5}$ с равномерным $(b, e, h, k)$ и линейным $(c, f, i, l)$ распределением заряда; контроль $(a, d, g, j)$.

ные клетки (ММСК) костного мозга, а также клетки двух типов соединительной ткани - скелетной (остеоциты и хондроциты) и собственно соединительной ткани (фибробласты кожи - ФК).

Клетки были выделены из донорских тканей с добровольного согласия доноров. В работе использовали клетки 2-5-го пассажей. Мультипотентные мезенхимные стромальные клетки, остеоциты и хондроциты культи- вировали в питательной среде $\alpha$ MEM (Lonzo, Бельгия) с добавлением 20\% FBS (HyClone, США). Фибробласты кожи - в питательной среде DMEM (HyClone, CША) с добавлением 10\% FBS (HyClone, США). Bce типы клеток культивировали при $37^{\circ} \mathrm{C}$ в $\mathrm{CO}_{2}$-инкубаторе в атмосфере $5 \% \mathrm{CO}_{2}$.

Влияние электрического поля медицинского электрета на жизнеспособность клеток исследовали в условиях 
in vitro в процессе их культивирования непосредственно на поверхности моделей танталовых ортопедических имплантатов с электретным покрытием. Жизнеспособность клеток оценивали по их морфологии и функциональной активности, используя методы сканирующей электронной микроскопии (СЭМ) и фотоколориметрического анализа (МТТ-тест).

Для оценки методом СЭМ воздействия электрического поля медицинского электрета на адгезию, распластывание и формирование монослоя клетками, культивируемыми непосредственно на поверхности электрета, танталовые диски помещали на дно лунок 12-луночных планшетов. На поверхность дисков наносили суспензию одного из четырех типов клеток (ММСК, остеоциты, хондроциты, ФК) в соответствующей питательной среде в концентрации $10^{5} \mathrm{cells} / \mathrm{cm}^{2}$ в виде капли и культивировали клетки на поверхности образцов тантала в стандартных условиях. Через одни сутки культивирования с помощью сканирующего электронного микроскопа JSM-35.7 (Japan) оценивали адгезию и характер прикрепления клеток к поверхности моделей ортопедических имплантатов, а через семь суток - формирование клетками монослоя на их поверхности.

Для оценки методом МТТ влияния электрического поля медицинского электрета на метаболическую активность клеток, культивируемых непосредственно на поверхности электрета, танталовые диски помещали на дно лунок 96-луночного планшета. В каждую лунку вносили суспензию клеток одного из вариантов $\left(5 \cdot 10^{3}\right.$ cells в $200 \mu 1$ соответствующей питательной среды) и культивировали в обычном режиме в течение пяти суток. По истечении срока культивирования проводили анализ МТТ. Оптическую плотность растворов измеряли с помощью анализатора Fluorofot „Charity“ (Россия) при длине волны $570 \mathrm{~nm}$ и референсной длине волны $630 \mathrm{~nm}$. Математическую обработку полученных данных проводили методами вариационной статистики при помощи программы Microsoft Excel 2007 и Statistica 10. Достоверность различий средних значений оптической плотности оценивали по $t$-критерию Стьюдента для независимых выборок. Различия считали достоверными при $p<0.05$.

\section{Результаты и обсуждение}

\section{Влияние электрического поля медицинского электрета на адгезию, распластывание и формирование монослоя клетками}

Метод сканирующей электронной микроскопии (СЭМ) позволяет оценить адгезивные свойства непрозрачных материалов, когда невозможна визуальная оценка морфологии клеток в процессе их культивирования на поверхности таких материалов методом световой микроскопии.

Через одни сутки после посева клетки всех типов адгезировали на поверхности всех танталовых дисков (экспериментальных и контрольных) и были хорошо распластаны (рис. 1), что подтверждает известные данные о высокой биологической совместимости тантала, широко применяемого в медицине в области восстановительной хирургии. Между тем были выявлены различия в морфологии клеток и характере их прикрепления к поверхности моделей имплантатов, предположительно связанные именно с наличием или отсутствием у них электретного покрытия. При отсутствии электретного покрытия (в контроле) ММСК (рис. 1,a), остеоциты (рис. $1, d$ ) и хондроциты (рис. $1, g$ ) через одни сутки после посева были широко распластаны с образованием множества фокальных контактов. На поверхности обоих вариантов электретов клетки принимали более вытянутую форму, у них появлялись структуры (выросты клеточной поверхности), характерные для активно мигрирующих клеток - псевдоподии, филлоподии, ламеллоподии (рис. $1, b, c, e, f, h, i$ ). Наиболее выраженными эти морфологические изменения были у хондроцитов на поверхности электретов с линейным распределением заряда (рис. $1, i$ ). У ФК в отличие от других клеток такие структуры наиболее выражены были в контроле (рис. $1, j$ ), а не на поверхности электретов (рис. $1, k, l$ ). Кроме того, были выявлены различия и в характере распределения клеток по поверхности дисков тантала, связанные с характером распределения электрического заряда по поверхности этих дисков. Через одни сутки после посева клеток на электретах с равномерным распределением заряда $\left(U_{e}=60-70 \mathrm{~V}\right)$ и в контроле ММСК, остеоциты и хондроциты располагались компактно по центру образцов, занимая площадь в форме круга. В то время как на электретах с линейным распределением заряда зона прикрепившихся клеток имела форму эллипса, вытянутого по градиенту $U_{e}$. У хондроцитов площадь этой зоны была значительно больше, чем у ММСК и остеоцитов, но с менее плотным расположением клеток в этой зоне относительно друг друга. Можно предположить, что такое расположение хондроцитов на электретах с линейным распределением заряда связано с усилением их миграционной активности под действием электрического поля данного электрета. Об этом могут косвенно свидетельствовать и выявленные при помощи СЭМ морфологические изменения, характерные для мигрирующих клеток, которые наиболее выраженными оказались именно у хондроцитов, культивируемых на электретах с линейным распределением заряда. Фибробласты кожи как в контроле, так и на электретах, располагались компактно по центру образцов, занимая площадь в форме круга.

Площадь зоны, занимаемой клетками на поверхности электретов и в контроле, увеличивалась в течение семи суток культивирования ФК, ММСК, остеоцитов и хондроцитов по сравнению с площадью, занимаемой клетками в течение одних суток культивирования. Учитывая, что все типы клеток сформировали плотный клеточный монослой в центральной части этой зоны, который к ее периферии носил более разреженный характер, можно 


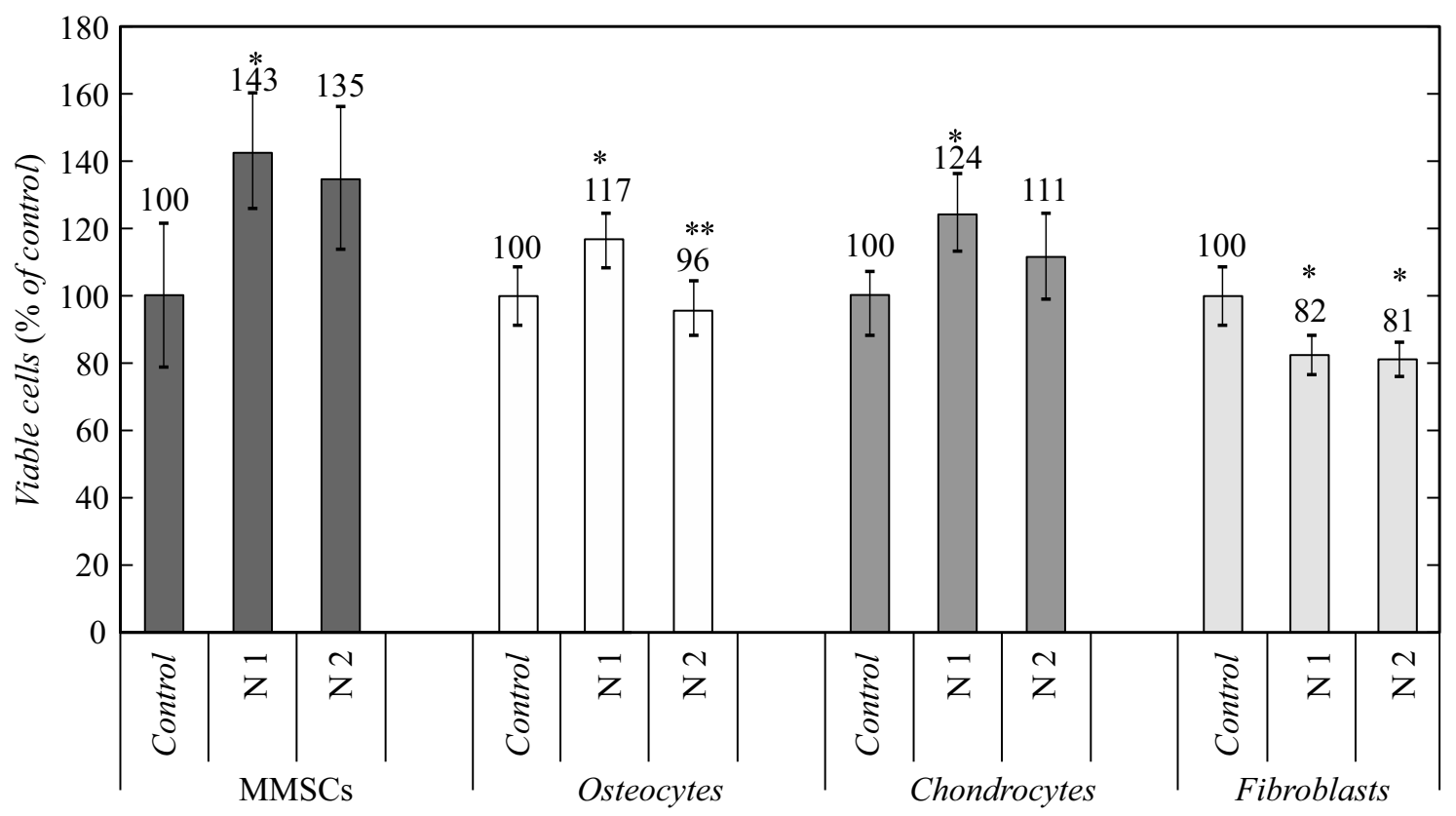

Рис. 2. Гистограммы оценки жизнеспособности различных типов клеток человека, культивируемых на поверхности медицинских электретов на основе $\mathrm{Ta}_{2} \mathrm{O}_{5}$. Контроль - образцы без электретного покрытия $\left(U_{e}=0\right)$; вариант электрета № 1 - образцы с равномерным распределением заряда $\left(U_{e}=60-70 \mathrm{~V}\right)$; вариант электрета № $2-$ образцы с линейным распределением заряда $\left(U_{e}\right.$ изменяется от 0 до $60-70 \mathrm{~V})$. МТТ-тест. ${ }^{*}-$ различия с контролем статистически значимы $(p<0.05)$; ${ }^{* *}-$ различия между экспериментальными вариантами № 1 и № 2 статистически значимы $(p<0.05)$.

предположить, что это связано с пролиферацией клеток и миграцией их по поверхности образцов. Причем форма зоны, занимаемой ММСК, остеоцитами и хондроцитами, осталась без изменений - эллипс на электретах с линейным распределением заряда (особенно выражено у ММСК и хондроцитов) и круг на электретах с равномерным распределением заряда и в контроле. ФК как в контроле, так и на электретах, занимали площадь в форме круга.

В то же время были выявлены различия в размерах площади монослоя, сформированного на поверхности танталовых дисков, и его плотности для разных типов клеток. Наиболее обширный по площади монослой на поверхности образцов сформировали остеоциты на седьмые сутки культивирования они практически полностью заняли поверхность дисков с электретным покрытием и без него (контроль). Монослой, сформированный остеоцитами на электретах обоих типов, был более плотным, чем в контроле. Это позволяет сделать предположение об усилении пролиферативной активности остеоцитов под действием электрического поля электретов.

За этот же срок культивирования область распространения ММСК по поверхности всех танталовых дисков при визуальной оценке оказалась значительно меньше, чем у остеоцитов. Причем на электретах обоих типов площадь, занимаемая монослоем, была чуть больше, чем в контроле. Однако плотность монослоя ММСК на всех дисках была значительно выше, чем у остеоцитов.
Вероятно, это может быть связано с более высокой пролиферативной активностью ММСК. На электретах выявлено несколько плотных зон монослоя ММСК, в то время как в контроле только одна - зона посева клеток. Можно предположить, что электрическое поле электретов оказало позитивное влияние на клонообразующую, пролиферативную и, возможно, миграционную потенцию ММСК.

Сформированный хондроцитами на всех дисках тантала монослой был менее плотным, чем монослой остеоцитов и ММСК. Вероятно, это связано с тем, что популяция хондроцитов является более медленно пролиферирующей по сравнению с другими популяциями стромальных клеток. Известно, что хрящевая ткань относится к тканям растущего типа, для которой характерно постепенное снижение митотической активности. Однако, как и у ММСК, монослой хондроцитов занял чуть больше половины площади поверхности электретов и чуть меньше половины площади поверхности в контроле, что может свидетельствовать о возможном стимулирующем влиянии электрического поля электрета в отношении миграционной и пролиферативной активности хондроцитов.

У ФК в отличие от ММСК, остеоцитов и хондроцитов наиболее выраженная функциональная активность выявлена у клеток, культивируемых на образцах без электретного покрытия (контроль). Монослой ФК в контроле занимал почти всю поверхность танталовых дисков и превосходил почти в два раза площадь монослоя, 
сформированного на электретах обоих типов. Возможно, действие поля электрета на основе $\mathrm{Ta}_{2} \mathrm{O}_{5}$ с электретной разницей потенциала до $70 \mathrm{~V}$ (при равномерном и линейном распределении отрицательного заряда) носит ингибирующий характер в отношении пролиферативной и/или миграционной активности фибробластов.

Результаты исследования методом СЭМ влияния электрического поля медицинского электрета на основе $\mathrm{Ta}_{2} \mathrm{O}_{5}$ на адгезивные свойства клеток различных типов сопоставимы с результатами исследования интенсивности их внутриклеточного метаболизма методом МТТ-теста.

\section{Влияние электрического поля медицинского электрета на метаболическую активность клеток}

МТТ-тест, широко известный как скрининговый метод измерения выживаемости клеток и включенный в большинство протоколов методов молекулярной биологии и медицины [22-24], позволяет оценить метаболическую активность клеток в данных условиях культивирования. Данный тест основан на способности дегидрогеназ живых клеток восстанавливать желтый водорастворимый 3-(4,5-диметилтиазолин-2)-2,5-дифенилтетразолий бромид (МТТ) в пурпурные внутриклеточные кристаллы формазана, нерастворимые в воде, но растворимые в диметилсульфоксиде (ДМСО). Количество образовавшегося формазана (определяемое колориметрическим методом после его растворения в органических растворителях) характеризует интенсивность окислительновосстановительных процессов в клетках. Только клетки с живыми митохондриями могут осуществлять эту реакцию, следовательно, интенсивность окраски прямо пропорциональна количеству живых митохондрий и живых клеток. Измерение концентрации формазана в растворе после взаимодействия с ДМСО позволяет оценить количество жизнеспособных клеток. МТТ-тест выявил различия по влиянию электрического поля электрета на метаболическую активность различных типов клеток человека. Результаты МТТ-теста представлены в виде гистограмм, где количество жизнеспособных клеток в контроле (танталовые диски без электретного покрытия) принято за $100 \%$ (рис. 2).

Было установлено, что жизнеспособность ФК, культивируемых в течение пяти суток на поверхности электретов как с равномерным, так и с линейным распределением отрицательного заряда оказалась достоверно ниже, чем в контроле. Возможно, действие поля электрета на основе $\mathrm{Ta}_{2} \mathrm{O}_{5}$ с электретной разницей потенциала до $70 \mathrm{~V}$ (при равномерном и линейном распределении отрицательного заряда) носит ингибирующий характер в отношении метаболической активности фибробластов. Жизнеспособность ММСК, остеоцитов и хондроцитов, культивируемых на поверхности электретов с равномерным распределением отрицательного заряда, напротив, оказалась достоверно выше, чем на образцах без электретного покрытия (контроль), что свидетельствует о благотворном действии электрического поля электрета в отношении этих клеток. При этом для остеоцитов отмечена достоверная разница в интенсивности метаболической активности клеток, культивируемых на различных вариантах электретов - она была выше на образцах с равномерным распределением заряда $\left(U_{e}=60-70 \mathrm{~V}\right)$. Можно предположить, что электрет на основе $\mathrm{Ta}_{2} \mathrm{O}_{5}$ с равномерным распределением по поверхности отрицательного электронного заряда плотностью $0.048-0.056 \mathrm{C} / \mathrm{m}^{2}$ с электретной разностью потенциалов между поверхностью оксида и танталом основы $U_{e}=60-70 \mathrm{~V}$ оказывает выраженное стимулирующее действие на остеоциты.

Полученные в условиях in vitro результаты позволяют косвенно прогнозировать стимулирующее влияние квазистатического поля электрета на пролиферативную, миграционную и метаболическую активность ММСК, остеоцитов и хондроцитов в области имплантатов с отрицательно заряженным электретным покрытием на основе $\mathrm{Ta}_{2} \mathrm{O}_{5}$, применяемых в травматологии. Учитывая, что именно эти клетки принимают активное участие в процессах репаративной регенерации опорнодвигательного аппарата, можно предположить, что применение электретов с заданными свойствами будет оптимизировать эти процессы. Данное предположение находит подтверждение в приведенных в литературе экспериментальных и клинических сведениях о благоприятном воздействии отрицательно заряженных электретов на процессы остеорепарации [15,16,18,20].

\section{Заключение}

Исследование, проведенное на клеточных культурах в условиях in vitro, показало, что электрическое поле электретных пленок $\mathrm{Ta}_{2} \mathrm{O}_{5}$ с электретной разницей потенциала до $70 \mathrm{~V}$ в зависимости от величины и распределения (равномерного или линейного) отрицательного заряда по поверхности электрета оказывает различное влияние на функциональную активность разных типов клеток. Было выявлено ингибирующее для фибробластов и стимулирующее для ММСК, остеоцитов и хондроцитов человека действие отрицательно заряженных танталовых электретов в отношении адгезии, пролиферативной, миграционной и метаболической активности клеток. Совокупность полученных данных свидетельствует об актуальности исследований влияния медицинских электретов на различные типы клеток, из которых состоят ткани и органы тела человека. Дальнейшие исследования влияния электрических полей медицинских электретов на функциональную активность различных типов клеток в условиях $2 D$ - и $3 D$-культивирования может способствовать более глубокому пониманию механизмов этого влияния с целью получения электретов с заданными свойствами для успешного применения в регенеративной медицине. 


\section{Список литературы}

[1] Макаревич А.В., Пинчук Л.С., Гольдаде В.А. // Электрические поля и электроактивные материалы в биологии и медицине. Гомель: ИММС НАНБ, 1998. 106 с.

[2] Гринберг Я.3. // Инженерный вестник Дона. 2014. № 4. Ч. 2. Электронный ресурс. Режим доступа: ivdon.ru/ru/magazine/archive/n4p2y2014/2644

[3] Блайт Э.Р., Блур Д. // Электрические свойства полимеров. М.: Физматлит, 2008. 377 с.

[4] Электреты / Под ред. Г. Сесслера. М.: Мир, 1983. 487 с.

[5] Eguchi M. // Phil. Mag. 1925. Vol. 49. P. 178.

[6] Галиханов М.Ф., Дебердеев Р.Я. // Вестник Казанского технологического университета. 2010. № 4. С. 45-57.

[7] Кулин E.T. // Биоэлектретный эффект. Минск: Наука и техника, 1980. $216 \mathrm{c.}$

[8] Кулин E.T. // Медицинские новости. 1996. № 10. С. 34-43.

[9] Цветкова Е.А., Гольдаде В.А. // Проблемы физики, математики и техники. 2012. № 1 (10). С. 51-58.

[10] Fukada E., Takamatsu T., Yasuda I. // Jpn. J. Appl. Phys. 1975. Vol. 14. P. 2079-2080.

[11] Ficat J.J., Escourrou G., Fauran M.J. et al. // IEEE International Symposium on Applications of Ferroelectrics, Gaithersburg USA. 1983.

[12] Graf H.-L., Stark W.D., Geiss D.R. // Proc. of the $5^{\text {th }}$ International Symposium on Electrets (ISE 5). Heidelberg, 1985. P. $813-818$.

[13] Hua J., En-tan G. // Plast. Reconstr. Surg. 1997 Vol. 100. N 4. P. 1075-1076.

[14] Valentini R.F., Sabatini A.M., Dario P., Aebischer P. // Brain Res. 1989. Vol. 480. N 1-2. P. 300-304.

[15] Эволюция остеосинтеза. Сб. науч. трудов / Под ред. А.И. Грицанова, В.П. Хомутова. СПб: МОРСАР АВ, 2005. $280 \mathrm{c}$.

[16] Копышев М.A. // Применение электретов в медицине. С.-Пб: Научно-производственная фирма „ЭЛМЕТ“, 2006. Электронный ресурс. Режим доступа: http://www.argo-shop.com.ua/library-6077.html

[17] Руднев В.С., Медков М.А., Килин К.Н., Устинов А.Ю., Белобелецкая М.В., Стеблевская Н.И., Мутылина И.Н., Жеребцов Т.О. // Физикохимия поверхности и защита материалов. 2013. Т. 49. № 6. С. 654-660.

[18] Линник С.А., Хомутов В.П., Моргунов М.С. // РМЖ. 2017. № 20. C. $1-4$.

[19] Фишман М., Княжсанская М., Немеи, А., Цун А. // Альманах клинической медицины. 2017. Т. 45. № 3. С. 234-241.

[20] Хомутов В.П., Ласка В.Л. // Петербургский журнал электроники. 1997. № 2 (15). С. 3-9.

[21] Makohliso S.A., Valentini R.F., West J.E., Aebischer P. // Proc. of the $7^{\text {th }}$ International Symposium on Electrets (ISE 7). Berlin, 1991. P. 712-716.

[22] Mosmann T. // J. Immunol. Methods. 1983. Vol. 65. N 1-2. P. 55-63.

[23] Cancer cell culture: methods and protocols. Ser. Methods in Molecular Medicine / Ed. by S.P. Langdon. Totowa, NJ: Humana Press, 2003. Vol. 88. P. 165-169.

[24] In vitro toxicity testing protocols. Ser. Methods in Molecular Biology / Ed. by S. O'Hare, C.K. Atterwill. Totowa, NJ.: Humana Press, 1995. Vol. 43. P. 138-149. 